\title{
Review
}

Journal of Hard Tissue Biology 19[1] (2010) p1-4

\section{Enamel and Forensic Odontology - Revealing the Identity}

\author{
Chetana Chandrashekar ${ }^{1)}$, Masanori Takahashi ${ }^{2)}$ and George Miyakawa ${ }^{2)}$
}

\author{
1) Department of Oral Pathology, Manipal College of Dental Sciences, Manipal- 576102, Karnataka, India. \\ ${ }^{2}$ Department of Legal Medicine, School of Medicine, Toho University 5-21-16,oomorinishi oota-ku Tokyo, 143-8540, Japan. \\ (Accepted for publication, January 10, 2010)
}

\begin{abstract}
Teeth have been extensively used as a source of information in human identification, especially when the soft tissue cannot provide reliable information. Dental enamel is the most mineralized tissue, and resists post-mortem changes. The enhanced probability of personal identification from histological stress markers is said to be due to the pattern being specific to an individual. The timing of birth preserved in enamel, termed the neonatal line is a predictable consequence of the birth process and occupies a characteristic position and can be used in the assessment of pathological striae and has medico-legal implications. Though Amino acid racemization in dentin is extensively studied, enamel also offers certain advantages. Enamel can be used for sex determination based on AMEL gene using molecular biology. These highlight the importance and potential of enamel in forensic dental identification.
\end{abstract}

Key words: Enamel, Forensic odontology, Neonatal line, Striae of retzius

\section{Introduction}

As human identification is becoming important in modern life, so is the use of dental identification in search for identity. Thus, teeth have been used extensively in individualization as a source of information especially when the soft tissues cannot provide reliable information. Enamel is a hard layer of highly mineralized tissue on the surface of the tooth and is resistant to postmortem degradation. Here an attempt has been made to highlight the different ways in which dental enamel can be used as a tool in forensic science for identification.

\section{Incremental Growth markers in Enamel}

Enamel is a hard mineralized tissue on the surface of the teeth, varying in thickness from a maximum of approximately $2.5 \mathrm{~mm}$ over working surfaces to a feather edge at he cervical line, composed of tightly packed prisms. ${ }^{1)}$ Enamel formation begins at the tip of the dentine horn, and proceeds by apposition towards the future surface of the tooth and by extension towards the future cervix of the tooth. Initially, a highly organic enamel matrix is secreted which is eventually replaced almost entirely by minerals, which are arranged in crystallized bundles that make up fundamental units, enamel prisms. During this process, changes in the enamel secretory rhythm, chemical composition are recorded as

Correspondence to: Chetana Chandrashekar, Assistant Professor, Department of Oral Pathology, Manipal College of Dental Sciences, Manipal- 576102, Karnataka, India. Tel No: +91 820 2922204, Email id: bhattu16@yahoo.co.in incremental structures. ${ }^{2)}$ The age at death and timing of physiologically stressful episodes can potentially be determined with some amount of precision as enamel is deposited in successive layers, the layering being observed as cross striations. In sections parallel to long axis of teeth, regular markings are observed along enamel prisms approximately three to four $\mathrm{mm}^{2}$. It has been widely argued but confirmed that the cross striations represent circadian rhythm and that it is possible to make reliable counts ${ }^{2,3)}$.

Cross striations are counted beginning from the first layer formed above dentin horn to the last layer formed immediately prior to death. To record the entire history, photomontages of each tooth are matched by wider spaced lines called Brown Striae of Retzius believed to be the result of near weekly (circaseptan) variation in structure of ename ${ }^{1.3)}$ The pattern of these striae in enamel is the same in all those parts of enamel formed at the same time in a given dentition. Thus different teeth developing in one individual give the same pattern of incremental lines, distinct from that of another individual. The pattern has been said to be a kind of fingerprint of enamel development specific for an individual. The pattern and timing of such lines can be matched to pre-mortem record of an individua ${ }^{13,4)}$.

For any individual, count of prism cross striations between regular (physiologic, rhythmic) Striae of Retzius is constant throughout all teeth. Authors have also distinguished pathological striae (systemic disturbances acting as individualizing signature patterns) within enamel which appears darker, broader (accentuated). These variations affect all the enamel matrix being formed at a given 


\section{J.Hard Tissue Biology Vol. 19(1):1-4, 2010}

time in a child, so that these can be used to match different teeth from one dentition. They can be used as reference points by which cross striation counts can be transferred between different parts of one cross section and between sections from different teeth in one individual.3,4

\section{Neonatalline}

The timing of birth preserved in enamel, termed the neonatal line is a predictable consequence of the birth process and occupies a characteristic position. This accentuated Striae is special, which marks the event of birth. It is found in all deciduous teeth as they start to form enamel matrix in utero, and usually but not always found in earliest enamel formed of first permanent molar. It is an important reference point to start cross-striations count. The neonatal line is said to be caused due to decreased plasma calcium in first 48 hours after birth or could be due to trauma associated with birth. It extends obliquely from surface to dentino-enamel junction. It is less densely mineralized and is said to be at a constant level within the tooth and shifts cervically as gestation is prolonged. ${ }^{5)}$ Thus, these enamel incremental structures / regular microscopic structures in enamel, offer a powerful tool in reconstructing dental development and crown formation of modern and archeological remains. They also determine the age at death of remains of children whose dentition are still forming at the time of death. Cross striations provide detailed sequences from which the timing and duration of growth disruptions seen as hypocalcified defects and accentuated striae can be established.

\section{Hunter schreger bands}

Enamel is characterized by the presence of Hunter Schreger bands which results from an optical phenomenon because of enamel prisms, as dark and light bands in light microscope. Hunter Schreger bands in enamel have been observed to closely resemble a fingerprint as they form minuitiae (points at the ending lines and at bifurcations when one line splits into two). Hence they have also been referred to as toothprints. Due to its similarity to fingerprint it has been used as biometric based method of identification using fingerprint identification/ verification software. Each tooth thereby is matched with the teeth stored in the database. Also this toothprint is distinct from that of its homologous tooth on the opposite side making it highly specific and unique for each tooth in an individual. This might complement fingerprint and DNA analysis and also other methods of identification. It can be clearly observed and seen in teeth burned at temperature up to $3000 \mathrm{C}$ for one hour. They can withstand extreme environmental conditions and are preserved after skin decomposition. It is Non invasive, accurate and readily performed in automated systems and could be a suitable physiological biometric trait for human personal identification ${ }^{6}$.

\section{Amino acid racemization}

In Forensic Science, various methods have been used for the esti- mation of chronological age. However Majority of age estimation methods both morphological and histological techniques on bone or dental elements are highly subjective ${ }^{7}$. Amino acid racemization, based on age-dependent non enzymatic changes of L- form to D-form amino acids is considered to be one of the most reliable and accurate methods ${ }^{8)}$.

Amino acids are building blocks from which proteins are formed and they exist in 2 forms L and D. When they are formed in the body, all amino acids are in L-form, but during the life of proteins they are converted to a mix of $\mathrm{L}$ and $\mathrm{D}$ forms by process of racemization and the rate is influenced by various factors like temperature, humidity, $\mathrm{pH}$. Therefore organs with low metabolic rates like teeth, bone and cartilage, barin cells and crystalline lens are better suited for age estimation than those with high metabolic rates. 8 Among dental tissues, enamel, dentin and cementum may be used for racemization. ${ }^{910.11 .12 .13 .14)}$ Aspartic acid racemization in dentin is well established method for age estimation in forensic research. Dentin is the tissue of choice as it forms early in life and undergoes little biochemical turnover during life. But the disadvantage is that it is problematic in remains with postmortem interval of more than 20 years. 12 Protein present in dentin is collagen and racemization of Aspartic acid residues (Asx residues) in collagen is controlled by highly ordered molecular structure. Succinimide formation, the pathway for peptide bound Asx racemization is effectively prevented in extended polypeptide backbone of collagen thereby restricting the sites of racemization to those Asx residues in the short flexible telopeptides at either end of molecule, which contain only $6 \%$ of the total Asx residues in type I Collagen. These take almost a century to undergo racemization at $370 \mathrm{C}$, so amino acid racemization in dentin can be used best in recently deceased individuals. ${ }^{12)}$

Though Amino acid racemization in dentin has been used successfully, this method cannot be used in remains where postmortem interval is greater than $20 \mathrm{yrs}$. An alternative is amino acid racemization in enamel which is highly resistant to postmortem changes. Enamel also forms early in life and undergoes little biochemical turnover, and contains no collagen. Proteins of mature enamel are processed during maturation by proteolytic enzymes to form Low molecular weight peptides which lack secondary and higher order structure that would restrict succinimide formation. It has also been shown that racemization could be derived from intracrystalline proteins. During enamel formation, enamel proteins are entrapped in growing crystalline structure, providing better source of intracrystalline proteins than in dentin. An additional advantage is that enamel is resistant to changes in burial environment. But the protein levels are very low and present a real analytical challenge. It has been shown that racemization in enamel shows a steady increase with age, and has the potential to be used in age estimation of skeletal remains ${ }^{12)}$. 
Chetana Chandrashekar et al.: Enamel and Forensic Odontology

The shape, morphology and dimensions of teeth and also recently DNA analysis have been used to identify the sex of the individual. Very minute quantity of DNA (as little as $20 \mathrm{pg}$ ), from very old specimens of teeth can be used. The sex of skeletal bones/ teeth can be rapidly determined with enormous accuracy in a segment of human $\mathrm{X}$ and $\mathrm{Y}$ chromosome encoded AMEL gene. There are significant differences in amelogenin protein synthesized from $\mathrm{X}$ and $\mathrm{Y}$ chromosomes. The Male has two different AMEL genes, one on $\mathrm{X}$ chromosome and one on $\mathrm{Y}$ chromosome, while the female has two identical genes on $\mathrm{X}$ chromosome. Thus AMEL gene that encodes for female amelogenin is located on $\mathrm{X}$ chromosome and for male is located on Y chromosome. Difference in size and pattern of these two genes is sufficient enough to be used as sensitive sex determinant for very small samples of DNA from unknown dental remains. This distinction between male and female AMEL genes is specific, sensitive and cost effective form modern foren$\operatorname{sics}^{15)}$.

\section{Conclusion}

Enamel, being a hard calcified tissue, resistant to degradation can be analyzed by various techniques like enamel histology, chemical quantitative method and DNA analysis in human personal identification.

\section{References}

1. Nanci A. Enamel: composition, formation and structure. In Ten cate's Oral Histology Development, structure and function, 141-190, Mosby Elsevier, 2008

2. Smith TM. Experimental determination of the periodicity of incremental features in enamel. J Anat. 208(1): 99-113, 2006

3. Antoine D, Hillson S and Dean MC. The developmental clock of dental enamel. a test for the periodicity of prism crossstriations in modern humans and an evaluation of most likely sources of error in histological studies of this kind. J. Anat. 214: 45-55, 2009

4. Skinner M and Anderson GS. Individualization and enamel histology: a case report in forensic anthropology. J Forensic
Sci 36: 939-948, 1991

5. Skinner M and Dupras T. Variation in Birth timing and location of the neonatal Line in human enamel. J Forensic Sci 38(6): 1383-90, 1993

6. Ramenzoni LL and Line SRP. Automated biometrics-based personal identification of the Hunter-Schreger bands of dental enamel. Praoc R Soc B 273:1155-1158, 2006

7. Waite ER and Collins MJ, Ritz-Timme S, Schutz HW, Cattaneo $\mathrm{C}$ and Borrman HI. A review of the methodological aspects of aspartic acid racemisation analysis for use in forensic science. Forensic Sci Int 103:113-24, 1997

8. Ohtani S and Yamamoto T. Strategy for the estimation of chronological age using the aspartic acid racemisation method with special reference to coefficient of correlation between D/L ratios and ages. J Forensic Sci 50:1020-7, 2005

9. Ohtani S and Katsuichi Y. Estimation of age from a tooth by means of racemisation of an amino acid especially aspartic acid-comparison of enamel and dentin. J Forensic Sci 37: 1061-7, 1992

10. Ohtani $\mathrm{S}$ and Katsuichi Y. Age estimation using the racemisation of amino acid in human dentin. J Forensic Sci 36: 792-800, 1991

11. Helfman PM and Bada JL. Aspartic acid racemization in the enamel from Living humans. Proc Nat Acad Sci 72: 2891-94, 1975

12. Griffin RC, Moody H, Penkman KEH and Collins MJ. The application of amino acid racemization in the acid soluble portion of enamel to the estimation of the age of human teeth. Forensic Sci Int 175:11-16, 2008

13. Ohtani S. Studies on age estimation using racemization of aspeartic acid in cementumJ Forensic Sci 40(5): 805-7, 1995

14. Ohtani S, Sugimoto H, Sugeno H, Yamamoto S and Yamamoto $\mathrm{K}$. Racemization of aspartic acid in human cementum with age. Arch Oral Biol 40(2): 91-5, 1995

15. Slavkin HC. Sex, enamel and forensic dentistry: A search for identity. J Am Dent Assoc 128: 1021-25, 1997 
J.Hard Tissue Biology Vol. 19(1):1-4, 2010 